NBER WORKING PAPER SERIES

\title{
HEALTH PLAN PAYMENT IN MEDICAID MANAGED CARE: A HYBRID MODEL OF REGULATED COMPETITION
}

\author{
Timothy Layton \\ Alice K. Ndikumana \\ Mark Shepard \\ Working Paper 23518 \\ http://www.nber.org/papers/w23518 \\ NATIONAL BUREAU OF ECONOMIC RESEARCH \\ 1050 Massachusetts Avenue \\ Cambridge, MA 02138 \\ June 2017
}

This essay was prepared as a chapter in "Risk Adjustment, Risk Sharing, and Premium Regulation in Health Insurance Markets: Theory and Practice" edited by Thomas McGuire and Richard van Kleef and published by Elsevier. We thank the editors for helpful comments. The views expressed herein are those of the authors and do not necessarily reflect the views of the National Bureau of Economic Research.

At least one co-author has disclosed a financial relationship of potential relevance for this research. Further information is available online at http://www.nber.org/papers/w23518.ack

NBER working papers are circulated for discussion and comment purposes. They have not been peer-reviewed or been subject to the review by the NBER Board of Directors that accompanies official NBER publications.

(C) 2017 by Timothy Layton, Alice K. Ndikumana, and Mark Shepard. All rights reserved. Short sections of text, not to exceed two paragraphs, may be quoted without explicit permission provided that full credit, including ( $)$ notice, is given to the source. 
Health Plan Payment in Medicaid Managed Care: A Hybrid Model of Regulated Competition Timothy Layton, Alice K. Ndikumana, and Mark Shepard

NBER Working Paper No. 23518

June 2017

JEL No. I13,I18

\section{ABSTRACT}

Medicaid, the government program for providing health insurance to low-income and disabled Americans, is the largest health insurer in the United States with more than 73 million enrollees. It is also the sector of the U.S. public health insurance system that relies most heavily on the tools of regulated competition with more than $60 \%$ of its enrollees enrolled in a private health plan in 2014. However, regulated competition in Medicaid differs from the typical model, emphasizing the tools of competitive procurement -- such as competitive bidding, the threat of exclusion from the market, and auto-assignment of enrollees to plans -- to attempt to improve efficiency, instead of relying primarily on the forces of consumer demand. In this paper, we discuss how Medicaid combines the tools of competitive procurement with the tools of regulated competition and some potential consequences of this hybrid model.

Timothy Layton

Harvard Medical School

Department of Health Care Policy

180 Longwood Avenue

Boston, MA 02115

and NBER

layton@hcp.med.harvard.edu

Alice K. Ndikumana

Harvard Medical School

Department of Health Care Policy

180 Longwood Avenue

Boston, MA 02115

andikumana@g.harvard.edu
Mark Shepard

Harvard Kennedy School

Mailbox 114

79 JFK Street

Cambridge, MA 02138

and NBER

mark_shepard@hks.harvard.edu 


\section{Introduction}

Medicaid, the public program for providing low-income and disabled Americans with health insurance coverage, is the largest payer for health care services in the United States. As of August 2016, over 73 million Americans (almost one quarter of the U.S. population) were enrolled in the Medicaid program (CMS 2016a). In 2015, total Medicaid spending exceeded $\$ 550$ billion (almost one-fifth of total U.S. healthcare spending) (Kaiser Family Foundation 2016).

Unlike Medicare, a federal program that is nationwide and uniform across states, Medicaid is a joint state-federal program. The federal government provides substantial funding for the program and in return regulates which populations must be covered by a state's Medicaid program and what benefits must be provided. States, in turn, have significant flexibility to cover additional populations and provide additional benefits. Importantly, states can also choose whether to provide Medicaid benefits through a publicly managed fee-for-service (FFS) program or to contract out the provision of Medicaid benefits to private managed care organizations (MCOs), also known as Medicaid Managed Care (MMC) plans. Over time, states have increasingly moved toward managed care, with around $60 \%$ of Medicaid recipients enrolled in a private managed care plan by 2014 (CMS 2016b). As part of these MMC programs, states often let individuals choose among multiple competing MMC plans and/or between a private MMC plan and a public FFS Medicaid plan - an arrangement similar to competition between private Medicare Advantage plans and Traditional Medicare.

As in the other individual health insurance markets covered in this volume, Medicaid managed care exhibits some features of regulated competition, though, as we explain below, 
MMC uses a unique and interesting flavor of regulated competition that leverages procurement rules to introduce the forces of competition at the initial procurement stage rather than at the level of consumer plan choice. In a sense, state Medicaid agencies can use their regulatory position to construct a low-cost, high-quality "network of health plans" - analogous to how health plans themselves attempt to construct low-cost, high-quality networks of healthcare providers.

State experimentation with regulated competition in Medicaid began in the early 1970s, with California leading the way (Sparer 2012). Growth was slow until the "managed care revolution" of the 1990s when managed care enrollment increased dramatically both in Medicaid and in other sectors of the U.S. health insurance market. However, managed care in Medicaid continued to grow dramatically even during the subsequent "managed care backlash" in the late 1990s and 2000s. By 2014, 60\% of Medicaid recipients were enrolled in a private MMC plan (CMS 2016b). ${ }^{1}$ Most of the initial enrollment in MMC was concentrated among pregnant women, mothers, and children, but more recently MMC enrollment has been growing among aged, disabled, and chronically ill Medicaid recipients (MACPAC, 2011).

In addition to the expansion of managed care enrollment, there has been an increase in the use of regulated competition principles by MMC programs. Initially, when states adopted managed care, payments to health plans were negotiated individually with each plan on an annual basis; risk adjustment was primitive and limited to demographics and eligibility category;

\footnotetext{
${ }^{1}$ Often estimates of Medicaid managed care penetration of $70 \%$ or higher are cited by policymakers and researchers. The "greater than 70\%" estimates include additional forms of "managed care," specifically the use of "primary care case management" (PCCM) programs. These programs are essentially government-run fee-for-service plans with bonuses to primary care providers for each Medicaid PCCM enrollee in their panel. The use of this type of "managed care" arrangement does not fit the mold of regulated competition, and, thus, for the purpose of this paper we do not count it as managed care.
} 
and "competition" consisted of one plan competing with the public FFS plan. Today, plan payments are often either based on competitive bids or set administratively, more sophisticated risk adjustment is widely used, and competition among MMC plans is more robust in many areas. Increasingly, MMC programs look like traditional health insurance markets organized around the principles of regulated competition - including markets like Medicare Advantage and national health insurance systems in the Netherlands, Germany, and Switzerland.

While MMC is adopting more features of regulated competition, its design is also rooted in its history as a public program for the poor. In many ways, state Medicaid programs treat MMC plans as contractors administering welfare benefits rather than as competitors in a regulated health insurance market. This theme shows up in several ways in MMC programs. First, there are generally no premiums in Medicaid. The program is largely free to recipients. While a few states have adopted nominal premiums for select (and small) populations, these premiums are charged for entry into Medicaid, not based on a recipient's plan choice. In other words, even when they exist, Medicaid premiums do not vary across plans. This implies that insurers cannot "pass through" any savings to Medicaid enrollees in the form of lower premiums. As we discuss below, this policy effectively rules out the standard form of price competition used in typical markets and which was a key principle of Enthoven and Kronick's (1989) regulated competition model. Instead, this channels consumer-driven competition into the quality-dimension of the product. This forces state Medicaid agencies to employ other tools to restrain spending growth, such as administrative rate-setting, exclusion of high price plans from the market, and autoassignment targeted to lower-price plans.

Second, most benefits (including cost sharing and covered services) are fixed across plans, following a state-specified schedule. Per federal rules, this schedule has minimal cost-sharing, 
removing demand-side incentives from the insurer's toolkit for encouraging efficient use of health care. This design is based on the idea that almost any cost sharing is considered "unaffordable" for indigent Medicaid recipients and therefore an undue barrier to accessing care. Insurers do, however, have flexibility to design medical provider networks (subject to minimum network adequacy rules), prescription drug formularies, and utilization review/care management practices.

Finally, health plan choice differs substantially from the traditional model of regulated competition. Many Medicaid recipients fail to actively choose an MMC plan, leaving the state to administratively assign them to one - assignment which is often random or quasi-random. States often use this assignment policy as part of the contracting process with MMC plans. A common policy is to use assignment to equalize market share, effectively ensuring all plans with a contract receive an adequate number of enrollees. More recently, as we describe in more detail below, states have also begun to experiment with assignment rules that are tied to elements of a plan's bid such as the plan's capitation rate or plan quality ratings.

It is also important to understand that unlike Medicare, Medicaid differs substantially across states, making it not one program but 52 programs (50 states + D.C. and Puerto Rico). States differ both in whether they use managed care at all and in which features of regulated competition they adopt. For example, some states like Connecticut do not contract with private managed care plans, relying exclusively on the public fee-for-service plan. This is becoming less common, however, with only ten states not enrolling at least some Medicaid recipients in a 
private MMC plan in 2014 (CMS, 2016b). ${ }^{2}$ On the other hand, states like New York have robust managed care programs that use regulated competition principles like plan choice, open enrollment periods, and risk adjustment. Then there are states like Missouri, which uses administratively-set government payments to plans but restricts entry to three plans per region via a competitive procurement process aimed at extracting the highest level of quality out of the competing health plans. Using the state's power over entry into the market as a tool to improve outcomes is an example of how procurement policy can shape competitive dynamics in Medicaid markets. This tool perhaps represents a new instrument to be considered in the "regulated competition" toolkit. This can also be thought of as a form of "selective contracting," analogous to the way health plans use the threat of exclusion from their provider networks to induce competition among providers.

Because of these significant differences across states, instead of going into great detail describing a particular state's payment system, below we attempt to describe broadly how plan payment works across different types of states. The remainder of this paper is organized as follows. Section 2 discusses the organization of the MMC system. Section 3 discusses health plan payment design, and section 4 discusses the (very limited) research evaluating MMC plan payment. Section 5 concludes by discussing ongoing issues and reforms.

\section{Organization of the health insurance system}

The organization of the Medicaid Managed Care (MMC) health insurance system is complex. State MMC programs vary in plan design requirements, procurement methods, and

\footnotetext{
2 Throughout this paper we do not consider state Programs of All-Inclusive Care for the Elderly (PACE) as comprehensive Medicaid Managed Care plans. This differs from the CMS definition.
} 
plan options for beneficiaries. Each state, subject to federal regulations, defines a set of covered health services, allowable cost sharing amounts, and provider network adequacy requirements for participating managed care plans. Some states contract with any insurer that complies with its requirements. Other states are selective, contracting only with insurers that win a competitive procurement process on the basis of price and/or other features of plan bids, such as the use of alternative payment models, care management practices, and other state priorities. Prices (also known as "capitation rates") paid by the state Medicaid program to insurers may be determined through the competitive plan selection process or may be set administratively or through negotiation with private insurers.

Once a menu of plans has been determined, Medicaid recipients either choose a plan or are assigned to a plan, following the regulations of their state. If recipients choose their plan, their choice may be influenced by marketing, outreach programs, and brokers or "navigators" provided by Medicaid. In this section we will discuss plan design, procurement and choice in greater detail to provide an overview of how the Medicaid Managed Care health insurance market operates.

\subsection{Plan Design Regulations}

State Medicaid programs determine which benefits must be covered by managed care plans. This decision consists of three components. First, states decide which services will be covered in their Medicaid programs beyond the services required by the federal government (if any). Second, states decide who will provide the services: a private MMC plan, a specialty MCO, or the state's fee-for-service Medicaid program. Third, the state chooses certain parameters regulating how managed care plans provide the services. 


\section{Covered Services}

The federal government defines a set of mandatory benefits that states are required to provide for Medicaid enrollees, outlined in Table 1a. For example, Early and Periodic Screening, Diagnostic, and Treatment (EPSDT) services are required for enrollees under 21 years of age to facilitate early identification and diagnosis of physical and mental disorders, as well as early initiation of the appropriate treatment. States are also required to provide pregnancy related services, including pre-natal care, delivery, post-partum care, and family planning. Federal rules prohibit cost sharing for both EPSDT and pregnancy-related services.

States may elect to also provide optional benefits for Medicaid enrollees, listed in Table $1 \mathrm{~b}$. While prescription drug coverage is technically optional, all states provide the benefit, though 22 states require nominal copayments for covered drugs (KFF, 2017a). Other notable optional benefits include adult dental, physical therapy and rehabilitation, and optometry. Federal regulations require that benefits are equivalent across beneficiaries and across the state in duration, amount and scope (MACPAC, 2017).

\section{Managed Care Carve-Outs}

When states adopt managed care, they may not do so for all covered Medicaid services. Often, some covered benefits are "carved out" of managed care plan contracts and instead provided and financed via a separate insurance scheme, such as a limited benefit plan $^{3}$ or traditional FFS Medicaid. The most commonly carved out benefits are prescription drugs, behavioral health, and dental services. Table 2 outlines which states carved out each of these

\footnotetext{
${ }^{3}$ States may contract with insurers to provide a subset of benefits or services to enrollees, such as behavioral health, transportation, dental or prescription drugs. These contracts, referred to as "limited benefit plans" or "prepaid health plans," are generally paid through capitation. Enrollment into limited benefit plans may include managed care enrollees, fee for services enrollees, or both.
} 
services in 2014. States may carve out benefits that they conclude would be more effectively administered and financed outside of a comprehensive managed care plan. Carve-outs may also have the beneficial property of protecting services that may be vulnerable to risk selection. Frank et al. (1996) and Frank et al. (2000) note that MMC plans have strong incentives to inefficiently ration services that are predictably used by high-cost, unprofitable individuals. By removing these services from the MMC plan contracts and financing them separately, states can ensure access to these services is maintained under MMC.

Table 1a: Mandatory Covered Benefits

\begin{tabular}{|c|c|}
\hline \multicolumn{2}{|l|}{ Mandatory Benefits } \\
\hline Inpatient hospital services & Laboratory and X-ray services \\
\hline Outpatient hospital services & Nursing facility services (for ages 21 and over) \\
\hline Physician services & Nurse midwife services \\
\hline $\begin{array}{l}\text { Early and Periodic Screening, Diagnostic, and } \\
\text { Treatment services (for individuals under age 21) }\end{array}$ & $\begin{array}{l}\text { Certified pediatric or family nurse practitioner } \\
\text { services }\end{array}$ \\
\hline Family planning services and supplies & Rural health clinic services \\
\hline Federally qualified health centers & $\begin{array}{l}\text { Tobacco cessation counseling and } \\
\text { pharmacotherapy for pregnant women }\end{array}$ \\
\hline Freestanding birth centers & Non-emergency transportation to medical care \\
\hline \multicolumn{2}{|l|}{ Home health services } \\
\hline Source: Centers for Medicare \& Medicaid Services & (CMS) \\
\hline https://www.medicaid.gov/medicaid/benefits/list- & of honofitc/indox html \\
\hline
\end{tabular}


Table 1b: Optional Covered Benefits

\begin{tabular}{|c|c|}
\hline \multicolumn{2}{|l|}{ Optional Benefits } \\
\hline Prescribed drugs & Dentures \\
\hline $\begin{array}{l}\text { Intermediate care facility services for individuals } \\
\text { with intellectual disabilities }\end{array}$ & Personal care services \\
\hline Clinic services & Private duty nursing services \\
\hline Occupational therapy services & $\begin{array}{l}\text { Program of All-Inclusive Care for the Elderly } \\
\text { (PACE) services }\end{array}$ \\
\hline Optometry services & Chiropractic services \\
\hline Physical therapy services & Critical access hospital services \\
\hline Targeted case management services & $\begin{array}{l}\text { Respiratory care for ventilator dependent } \\
\text { individuals }\end{array}$ \\
\hline Prosthetic devices & Primary care case management services \\
\hline Hospice services & $\begin{array}{l}\text { Services furnished in a religious non-medical } \\
\text { health care institution }\end{array}$ \\
\hline $\begin{array}{l}\text { Inpatient psychiatric services for individuals } \\
\text { under age } 21\end{array}$ & Tuberculosis-related services \\
\hline Dental services & Home and community based services \\
\hline Eyeglasses & $\begin{array}{l}\text { Health homes for enrollees with chronic } \\
\text { conditions }\end{array}$ \\
\hline Speech, hearing, and language disorder services & Other licensed practitioners' services \\
\hline $\begin{array}{l}\text { Inpatient hospital and nursing facility services for } \\
\text { individuals age } 65 \text { or older in institutions for } \\
\text { mental diseases }\end{array}$ & $\begin{array}{l}\text { Emergency hospital services in a hospital not } \\
\text { meeting certain Medicare or Medicaid } \\
\text { requirements }\end{array}$ \\
\hline
\end{tabular}

Source: Centers for Medicare \& Medicaid Services (CMS)

https://www.medicaid.gov/medicaid/benefits/list-of-benefits/index.html

Behavioral health care is the most prominent example of a service often carved out of managed care contracts. Specialized behavioral health providers are often separate from the rest of the health care system - such as psychiatric hospitals or outpatient behavioral health clinics. Some 
professionals are non-physician health care providers who specialize in behavioral health, such as clinical social workers and psychologists. This separate nature of the behavioral health system is one reason why states may carve out these services from MMC plans. ${ }^{4}$ While carving out behavioral health has been the norm in MMC, a growing number of states have reversed course, "carving in" behavioral health into MMC plan contracts. Among the 42 states that offered MMC plans in 2014, 16 states carved out behavioral health (CMS 2016b) whereas in 2010, 21 of 36 states offering MMC plans carved out behavioral health (Gifford 2011).

States may also carve out benefits in response to federal policies. For example, prior to the Affordable Care Act (ACA), prescription drugs provided through MMC plans were not eligible for the Medicaid drug rebate program, which required pharmaceutical companies to provide substantial discounts to Medicaid programs. As of 2010, the rebate program was expanded to include drugs financed through MMC, prompting some states (such as New York) to carve prescription drug coverage into managed care plan contracts (MACPAC, 2011; KFF 2011).

\section{Regulation of MMC Plan Benefits}

Premiums and cost sharing are restricted to nominal levels in MMC plans, and prohibited for certain services and populations. Medicaid serves low-income individuals and families, for whom cost sharing typical in commercial insurance plans is perceived as unaffordable. Because of this, states impose maximum allowable amounts for premiums and cost sharing that vary by service, income level, and beneficiary type, in accordance with federal regulations. Cost sharing is prohibited for emergency services, family planning services, pregnancy-related services, or

\footnotetext{
${ }^{4}$ Behavioral health carve-outs are used in the private health insurance market as well. Large employers may contract separately with a managed behavioral health organization. Alternatively, an employer sponsored health plan may subcontract with a managed behavioral health organization.
} 
Table 2: Benefit Carve Out

Legend $\checkmark$ carved in

$x$ carved out

\begin{tabular}{|c|c|c|c|c|}
\hline State & Comprehensive MCO & Dental & Behavioral Health & Prescription Drugs \\
\hline Alabama & & -- & -- & -- \\
\hline Alaska & & -- & -- & -- \\
\hline Arizona & $\diamond$ & $\checkmark$ & $x$ & $\checkmark$ \\
\hline Arkansas & & -- & -- & -- \\
\hline California & 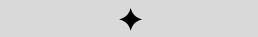 & $x$ & $x$ & $\checkmark$ \\
\hline Colorado & 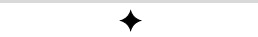 & $x$ & $x$ & $\checkmark$ \\
\hline Connecticut & & -- & -- & -- \\
\hline Delaware & 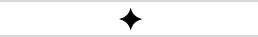 & $\checkmark$ & $\checkmark$ & $\checkmark$ \\
\hline District of Columbia & $\uparrow$ & $\checkmark$ & $\checkmark$ & $\checkmark$ \\
\hline Florida & $\diamond$ & $\checkmark$ & $x$ & $\checkmark$ \\
\hline Georgia & $\uparrow$ & $\checkmark$ & $\checkmark$ & $\checkmark$ \\
\hline Hawaii & 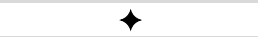 & $\checkmark$ & $\checkmark$ & $\checkmark$ \\
\hline Idaho & $\diamond$ & $\checkmark$ & $\checkmark$ & $\checkmark$ \\
\hline Illinois & $\uparrow$ & $x$ & $\checkmark$ & $x$ \\
\hline Indiana & $\diamond$ & $x$ & $\checkmark$ & $x$ \\
\hline lowa & $\uparrow$ & $x$ & $x$ & $\checkmark$ \\
\hline Kansas & $\uparrow$ & $\checkmark$ & $\checkmark$ & $\checkmark$ \\
\hline Kentucky & $\uparrow$ & $\checkmark$ & $x$ & $\checkmark$ \\
\hline Louisiana & $\uparrow$ & $x$ & $x$ & $x$ \\
\hline Maine & & -- & -- & -- \\
\hline Maryland & 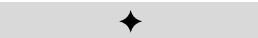 & $\checkmark$ & $x$ & $\checkmark$ \\
\hline Massachusetts & $\diamond$ & $\checkmark$ & $\checkmark$ & $\checkmark$ \\
\hline Michigan & $\diamond$ & $x$ & $x$ & $\checkmark$ \\
\hline Minnesota & $\diamond$ & $\checkmark$ & $\checkmark$ & $\checkmark$ \\
\hline Mississippi & 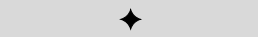 & $\checkmark$ & $x$ & $\checkmark$ \\
\hline Missouri & $\diamond$ & $\checkmark$ & $\checkmark$ & $x$ \\
\hline Montana & & -- & -- & -- \\
\hline Nebraska & $\diamond$ & $x$ & $x$ & $x$ \\
\hline Nevada & $\uparrow$ & $\checkmark$ & $\checkmark$ & $\checkmark$ \\
\hline New Hampshire & 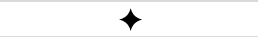 & $x$ & $\checkmark$ & $\checkmark$ \\
\hline New Jersey & $\diamond$ & $\checkmark$ & $\checkmark$ & $\checkmark$ \\
\hline New Mexico & $\uparrow$ & $\checkmark$ & $\checkmark$ & $\checkmark$ \\
\hline New York & 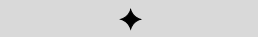 & $\checkmark$ & $\checkmark$ & $\checkmark$ \\
\hline North Carolina & & -- & -- & -- \\
\hline North Dakota & $\diamond$ & $\checkmark$ & $\checkmark$ & $\checkmark$ \\
\hline Ohio & $\diamond$ & $\checkmark$ & $\checkmark$ & $\checkmark$ \\
\hline Oklahoma & & -- & -- & -- \\
\hline Oregon & 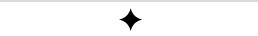 & $\checkmark$ & $\checkmark$ & $\checkmark$ \\
\hline Pennsylvania & 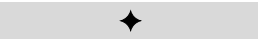 & $\checkmark$ & $x$ & $\checkmark$ \\
\hline Puerto Rico & 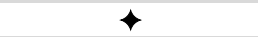 & $\checkmark$ & $x$ & $\checkmark$ \\
\hline Rhode Island & $\uparrow$ & $x$ & $\checkmark$ & $\checkmark$ \\
\hline South Carolina & $\uparrow$ & $x$ & $\checkmark$ & $\checkmark$ \\
\hline South Dakota & & -- & -- & -- \\
\hline Tennessee & $\diamond$ & $x$ & $\checkmark$ & $x$ \\
\hline Texas & 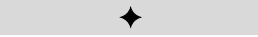 & $x$ & $\checkmark$ & $x$ \\
\hline Utah & $\diamond$ & $x$ & $x$ & $\checkmark$ \\
\hline Vermont & $\diamond$ & $\checkmark$ & $\checkmark$ & $\checkmark$ \\
\hline Virginia & $\diamond$ & $x$ & $\checkmark$ & $\checkmark$ \\
\hline Washington & $\downarrow$ & $x$ & $x$ & $\checkmark$ \\
\hline West Virginia & $\vdash$ & $\checkmark$ & $x$ & $\checkmark$ \\
\hline Wisconsin & 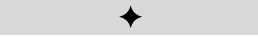 & $\checkmark$ & $\checkmark$ & Varies \\
\hline Wyoming & & -- & -- & -- \\
\hline Total Comp. MCO: & 42 & -- & -- & -- \\
\hline Total Carved In: & -- & 26 & 26 & 34 \\
\hline Total Carved Out: & -- & 16 & 16 & 7 \\
\hline
\end{tabular}

Source: Compiled from the Centers for Medicare and Medicaid Services (CMS) Managed Care State Profiles https://www.medicaid.gov/medicaid/managed-care/state-profiles/index.html 
preventive services for children (Brooks 2016). Furthermore, the sum of premium and cost sharing liabilities cannot exceed 5\% of a family's income. (Medicaid and Children's Health 2013).

Some cost sharing, however, is allowed in a few cases. For example, some states allow the use of variable copayments for prescription drugs to steer beneficiaries to more cost effective drugs included on a preferred drug list. Federal regulations limit the maximum allowable copay for prescription drugs to $\$ 4$ for preferred drugs and $\$ 8$ for non-preferred drugs, though state limits may be more restrictive. MMC plans may also elect to include lower cost sharing than the maximum allowed by the state. As a result, cost sharing may vary between MMC plan offerings and the fee-for-service option, or between participating MMC plan offerings.

While cost sharing is strictly regulated, MMC plans have more flexibility in other areas of plan benefit design. The most important area is provider network design. Medicaid plan provider networks are perceived as some of the narrowest in the American health insurance market (though hard evidence to support this perception is limited), indicating that MMC insurers use this tool to limit health care costs among their enrollees (Draper 2004; Mershon 2016). In practice, the de facto networks for these plans may be even smaller than the set of providers listed in the network. A 2013 study by the US Department of Health and Human Services found that about half of listed providers in managed care networks did not offer appointments to enrollees (OIG 2014).

Managed care plans are permitted to limit provider networks in accordance with network adequacy standards. Federal regulations require that all states define access standards for MMC plans to ensure that enrollees have adequate and timely access to all covered services. States must also develop a plan to monitor access, including an external review of access standards. 
Network adequacy standards must require MMC plans to consider anticipated enrollment, utilization and geographic location when constructing their provider network. If a covered service cannot be delivered by an in-network provider, a managed care plan must cover the service at an out-of-network provider with no additional cost to the beneficiary (OIG 2014).

MMC plans are generally health maintenance organizations (HMO) which do not cover outof-network services when an in-network provider is available. However, federal regulations require that MMC plans must cover out-of-network care for emergency and family planning services, both of which are also exempt from patient cost sharing. MMC plans are required to communicate which benefits may be obtained out-of-network and how to obtain those benefits. For example, insurers may require prior authorization for non-emergency services obtained at an out-of-network provider when an in-network provider was not available. Out-of-network providers are prohibited from billing the patient for the difference between the amount reimbursed by the MMC plan and the provider's customary charge. Additionally, payments to providers for out-of-network care are not governed by predetermined contracts. As a result, costly case-by-case negotiations between insurers and providers may arise to determine reimbursement. The 2005 Deficit Reduction Act attempted to address this issue by requiring providers to accept payments made for out-of-network emergency services at the equivalent Medicaid fee-for-service rate (Center for Medicaid and State Operations, 2006). Some states have established policies to govern reimbursement for non-emergency out-of-network payments as well. For example, in Florida, a Medicaid plan must reimburse an out-of-network provider the lesser of the Medicaid fee-for-service rate or the provider's customary charges (Lewin Group).

Federal network adequacy regulations discussed so far leave states considerable flexibility to develop state-specific network adequacy standards, leading to significant variations across states. 
Common criteria for network adequacy used by states include distance or time of travel to provider, availability of appointments within a given time frame, and a defined ratio of providers to enrollees. Standards may or may not be specified differently for different types of providers, such as a primary care provider (PCP) or obstetrician. Additionally, for a given network adequacy criterion, the exact requirement may vary significantly across states. For example, in 2013, among states that had a provision for the maximum enrollee-to-PCP ratio, the maximum allowed ratio varied from 100 enrollees per PCP to 2,500 enrollees per PCP (OIG, 2014).

\section{Textbox 1: MO HealthNet - Missouri’s Medicaid Program}

In most regions of Missouri, non-disabled adults and children as well as disabled Medicaid recipients are required to enroll in a private comprehensive MMC plan. Prior to 2012, Missouri allowed "any willing plan" to participate in its Medicaid managed care program, and paid plans using administratively-set rates. Rates were adjusted using demographic factors. There were three rating regions, and plans could choose which regions to enter. In each of the eastern and western regions, there was at least one hospital-owned plan in the program.

Starting in 2013, Missouri switched to a competitive bidding system. Under the new system, the state awards only three managed care contracts, and the plans must operate in all three rating regions. Plan bids do not include prices, however. Instead, bids are purely technical proposals that outline provider networks and how the plans will achieve a set of priorities outlined by the state including the adoption of medical homes and alternative payment models. This results in a procurement process that is highly subjective. The process is an example of a state that uses the threat of exclusion to attempt to extract higher levels of quality out of health plans for a given administratively-set payment.

Despite the subjectivity involved in the process, the threat of exclusion turned out to be highly credible: one large plan owned by Molina that had participated in MO HealthNet for a number of years was excluded in 2013, despite Molina's attempts to force the state to accept its contract via litigation. The three plans chosen to participate in the market were HealthCare USA (owned by Aetna), Home State Health Plan (owned by Centene), and Missouri Care (owned by Wellcare). Because the chosen plans were required to operate in all three regions of the state, local hospital-owned plans were effectively eliminated from the program.

Plan payments under the newly reformed program include a few interesting features. First, the state began to risk adjust payments using the Medicaid Rx risk adjustment model. The state decided to use the pharmacy-only model initially due to concerns about the completeness of 
diagnosis data for some health plans (Dockendorf et. al. 2014). Starting in 2015, the state began to pay under the CDPS+Rx model which incorporates both diagnoses and pharmacy information for risk adjustment. Second, plan payments include quality withholds, where the state doesn't pay plans the full payment until after the year is over and the state determines whether the plan met certain quality thresholds.

\subsection{Competitive Procurement}

States use varying procurement methods to select insurers for MMC programs. Some states contract with all insurers that meet specified requirements. Most states, however, use competitive procurement to select insurers on the basis of cost and/or other features of plan bids such as quality and proposals for fulfilling particular state priorities such as the adoption of alternative models of provider payment. States generally contract with MCOs for one to three years and may include an option for one-year renewals. ${ }^{5}$

Table 3 indicates which states use competitive vs. non-competitive selection methods. In a competitive procurement model, states issue a request for proposals (RFP) that informs insurers about the Medicaid program requirements and solicits a cost bid and/or a technical proposal from insurers. The cost bid may include factors such as the insurer's historical financial performance, administrative costs, projected costs for delivering Medicaid benefits, or a proposed capitation rate. States may communicate a range of acceptable (i.e. "actuarially sound") capitation rate bids in the RFP. In some cases, the cost bid is used to determine the capitation rate. Alternatively, some states use competitive procurement to select plans, but capitation rates are set administratively or through negotiation. ${ }^{6}$ Next, the technical proposal outlines the insurer's plan for delivering covered services in accordance with the state's regulations, incorporating

\footnotetext{
${ }^{5}$ For instance, Florida and Missouri have used one-year contracts with two one-year renewals for a total contract length of three years. Virginia has used one-year contracts.

${ }^{6}$ More details on rate-setting methods are provided in Section 3.
} 
information on provider networks and alternative provider payment models (e.g., use of medical homes or Accountable Care Organizations). Bids are reviewed by state Medicaid programs, and insurers are selected using state-specific rubrics that weigh the cost bid and technical proposal. ${ }^{7}$

The insurers that participate in MMC programs vary significantly in size, scope, and structure. Prior to 1997, there was a " $75 / 25$ " rule that required MMC insurers have at least 25 percent of their membership in the private, commercial health insurance market. The Balanced Budget Act of 1997 eliminated the " $75 / 25$ " rule, making it possible for Medicaid-only insurers to participate (MACPAC, 2011). This flexibility has led to the rise of insurers like Centene and Molina that focus almost exclusively on the MMC market. Nonetheless, more traditional, predominantly commercial insurers continue to participate in Medicaid managed care (KFF 2017b). For example, in 2016, Aetna and United Healthcare have MMC contracts with 12 and 22 states, respectively (KFF, 2017b). Insurers also vary by geographic scope, with some operating in a single state or region (or even metropolitan area) and others operating across states.

Another notable feature of Medicaid managed care insurance markets is the prevalence of small, local provider-owned insurers. Some safety-net hospitals and community health centers, which serve a high share of low-income, Medicaid-eligible patients, also operate MMC plans. These plans may operate within relatively small geographic areas - e.g., Metroplus in New York City or Chinese Community Health Plan (CCHP) in San Francisco. While providers have entered the insurance market with Medicaid plans, some Medicaid insurers have likewise entered the provider market by building their own health centers in areas with a high density of Medicaid

\footnotetext{
${ }^{7}$ In some states, such as Missouri, the MMC plan bids do not include a cost bid, thereby focusing the bid entirely on the technical proposal.
} 
Table 3: Procurement and Enrollment Options

\begin{tabular}{|c|c|c|c|c|c|}
\hline \multirow[b]{2}{*}{ State } & \multirow[b]{2}{*}{ Comprehensive MCO } & \multirow[b]{2}{*}{ Procurement Method } & \multicolumn{3}{|c|}{ Enrollment Option in Managed Care } \\
\hline & & & Adult & Child & Disabled \\
\hline Alabama & & -- & -- & -- & -- \\
\hline Alaska & & -- & -- & -- & -- \\
\hline Arizona & $\diamond$ & Competitive Selection & Varies & Varies & Varies \\
\hline Arkansas & & -- & -- & -- & -- \\
\hline California & 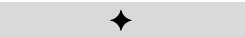 & $* *$ & Mandatory & Mandatory & Varies \\
\hline Colorado & 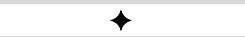 & $* *$ & Voluntary & Voluntary & Voluntary \\
\hline Connecticut & & -- & -- & -- & -- \\
\hline Delaware & $\uparrow$ & Competitive Selection & Mandatory & Mandatory & Mandatory \\
\hline District of Columbia & $\uparrow$ & Competitive Selection & Mandatory & Mandatory & Not Eligible \\
\hline Florida & $\hookrightarrow$ & $* *$ & Mandatory & Mandatory & Mandatory \\
\hline Georgia & $\hookrightarrow$ & Competitive Selection & Mandatory & Mandatory & Not Eligible \\
\hline Hawaii & 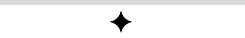 & Competitive Selection & Mandatory & Mandatory & Mandatory \\
\hline Idaho & 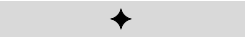 & Competitive Selection & Mandatory & Mandatory & Not Eligible \\
\hline Illinois & $\uparrow$ & Competitive Selection & Voluntary & Voluntary & Mandatory \\
\hline Indiana & 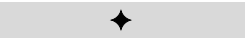 & Competitive Selection & Mandatory & Mandatory & Not Eligible \\
\hline lowa & 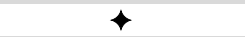 & $* *$ & Mandatory & Mandatory & Not Eligible \\
\hline Kansas & 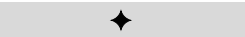 & Competitive Selection & Mandatory & Mandatory & Mandatory \\
\hline Kentucky & $\vdash$ & Competitive Selection & Mandatory & Mandatory & Mandatory \\
\hline Louisiana & $\uparrow$ & Competitive Selection & Mandatory & Mandatory & Varies \\
\hline Maine & & -- & -- & -- & -- \\
\hline Maryland & $\uparrow$ & Non-Competitive & Mandatory & Mandatory & Mandatory \\
\hline Massachusetts & $\uparrow$ & Competitive Selection & Mandatory & Mandatory & Varies \\
\hline Michigan & $\hookrightarrow$ & Competitive Selection & Varies & Mandatory & Mandatory \\
\hline Minnesota & $\hookrightarrow$ & Competitive Selection & Mandatory & Mandatory & Varies \\
\hline Mississippi & 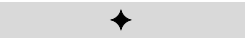 & Competitive Selection & Mandatory & Mandatory & Mandatory \\
\hline Missouri & 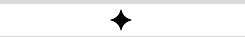 & Competitive Selection & Mandatory & Mandatory & Mandatory \\
\hline Montana & & -- & -- & -- & -- \\
\hline Nebraska & 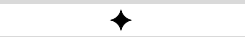 & Non-Competitive & Mandatory & Mandatory & Mandatory \\
\hline Nevada & 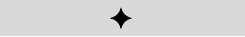 & Competitive Selection & Mandatory & Mandatory & Mandatory \\
\hline New Hampshire & $\uparrow$ & Competitive Selection & Mandatory & Mandatory & Mandatory \\
\hline New Jersey & $\uparrow$ & Competitive Selection & Mandatory & Mandatory & Mandatory \\
\hline New Mexico & 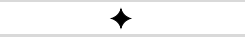 & Competitive Selection & Mandatory & Mandatory & Mandatory \\
\hline New York & $\hookrightarrow$ & Competitive Selection & Mandatory & Mandatory & Mandatory \\
\hline North Carolina & & -- & -- & -- & -- \\
\hline North Dakota & 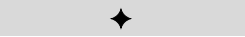 & $* *$ & Not Eligible & Not Eligible & Not Eligible \\
\hline Ohio & 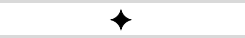 & Competitive Selection & Mandatory & Mandatory & Mandatory \\
\hline Oklahoma & & -- & -- & -- & -- \\
\hline Oregon & 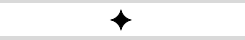 & $* *$ & Mandatory & Voluntary & Voluntary \\
\hline Pennsylvania & 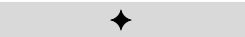 & Competitive Selection & Mandatory & Mandatory & Mandatory \\
\hline Puerto Rico & $\uparrow$ & Competitive Selection & Mandatory & Voluntary & Mandatory \\
\hline Rhode Island & $\downarrow$ & Competitive Selection & Mandatory & Mandatory & Mandatory \\
\hline South Carolina & 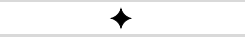 & Competitive Selection & Mandatory & Mandatory & Mandatory \\
\hline South Dakota & & -- & -- & -- & -- \\
\hline Tennessee & 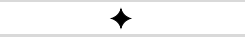 & Competitive Selection & Mandatory & Mandatory & Mandatory \\
\hline Texas & $\hookrightarrow$ & Competitive Selection & Mandatory & Mandatory & Mandatory \\
\hline Utah & 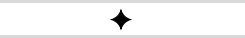 & Competitive Selection & Mandatory & Mandatory & Mandatory \\
\hline Vermont & 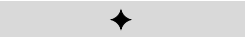 & Other & Mandatory & Mandatory & Mandatory \\
\hline Virginia & 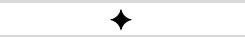 & Competitive Selection & Mandatory & Mandatory & Mandatory \\
\hline Washington & $\uparrow$ & Competitive Selection & Varies & Varies & Mandatory \\
\hline West Virginia & 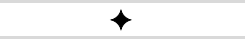 & Non-Competitive & Mandatory & Mandatory & Not Eligible \\
\hline Wisconsin & 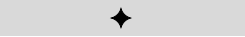 & Other & Mandatory & Mandatory & Mandatory \\
\hline Wyoming & & -- & -- & -- & -- \\
\hline
\end{tabular}

Legend $* *$ procurement method unknown

Non-competitive Procurement Method - States that use non-competitive procurement contract with any MCO that that agrees to meet their requirements.

Other Procurement Method - States use different procurement methods for different populations or regions or an alternative procurement method.

Source: Compiled from the Centers for Medicare and Medicaid Services (CMS) Managed Care State Profiles https://www.medicaid.gov/medicaid/managed-care/state-profiles/index.html 
eligibility. Examples of these are Trusted Health Plan in the District of Columbia and L.A. Care in Los Angeles.

\subsection{Plan Choice}

Plan choice in Medicaid varies significantly across states on a variety of dimensions. First, the enrollment options available to Medicaid beneficiaries vary by state and beneficiary type. Table 3 shows how these enrollment options vary across states. Medicaid beneficiaries are either (a) required to enroll in a managed care plan ("mandatory"), (b) given a choice between MMC and the publicly managed FFS Medicaid program ("voluntary"), or (c) excluded from MMC ("not eligible"). Federal rules require states that use MMC to provide Medicaid recipients with some form of choice, either between FFS and MMC or among different MMC plans. In the 1990s, Medicaid managed care served mainly low-income children and families, often via mandatory enrollment but sometimes as a voluntary choice. Aged and disabled Medicaid beneficiaries, who tend to have more complex health needs, were generally served by FFS Medicaid. More recently, states have started to enroll aged and disabled beneficiaries into managed care plans (MACPAC, 2011). Table 3 indicates that of the 42 states with Medicaid managed care programs in 2014, 28 of them required all disabled Medicaid recipients to enroll in an MMC plan.

Second, the enrollment process varies by state and recipient type. In some states, all new enrollees are pre-assigned to a managed care plan and then given a period of time during which they are allowed to switch. In others, there is an initial enrollment choice period (just after eligibility verification) for new enrollees to select a plan. During this choice period, recipients are covered by the FFS program. After the choice period, enrollees who do not make an active 
plan choice are "auto-assigned" to a plan using algorithms that vary by state. This enrollment process varies across states and within a state by recipient type. For example, pregnant women in Louisiana are pre-assigned, whereas other beneficiaries have a 30-day enrollment choice period.

In many states, auto-assignment -using an algorithm to automatically enroll Medicaid recipients who do not actively choose a plan in a (typically randomly) selected plan - is very common. A recent survey of state Medicaid programs found that the median state has an autoassignment rate of $45 \%$, with the auto-assignment rates for ten states exceeding $60 \%$ (Smith 2016). Auto-assignment algorithms sometimes consider existing provider-patient relationships and may also consider geographic location and enrollment of family members. In some states, preferential auto-assignment rewards plans with superior cost or quality performance. In many states, however, preferential auto-assignment focuses on balancing market shares across MMC plans - i.e., assigning more enrollees to the plans that fewer people have actively chosen. ${ }^{8}$ If enrollment in managed care is not mandatory, enrollees who do not make a plan selection may instead be enrolled in FFS Medicaid. ${ }^{9}$ Once the initial plan assignment has been made, enrollees are often given a period of time to freely switch plans, after which they are often 'locked-in' to a managed care plan for 6-12 months. However, the allowed time when enrollees can switch plans also varies across states. Even during the "open enrollment" period during which recipients can switch plans, assignments are relatively "sticky," with low levels of switching. However, switching is more likely among sicker recipients who tend to move from lower-quality to higher-

\footnotetext{
${ }^{8}$ This policy therefore rewards plans that - based on revealed preference in enrollees' active plan choices - appear to be less desirable. While this policy seems odd, it is consistent with the theme of MMC plans as contractors or partners in administering a welfare program (rather than competitors in a market). Auto-assigning more enrollees to smaller plans helps prop up these insurers, making them more likely to succeed and giving them more leverage in contract negotiations with providers.

${ }^{9}$ Massachusetts auto-assigns Medicaid recipients first to FFS vs. MMC and then those individuals who are assigned to $\mathrm{MMC}$ are auto-assigned to a specific MMC plan.
} 
quality plans, indicating that while auto-assignment may weaken adverse selection problems, it does not remove them entirely (Geruso, Layton, and Wallace 2017; Marton, Yelowitz, and Talbert 2017).

Plan choice can be influenced by marketing, outreach programs and support from insurance brokers. Most states allow insurers to conduct marketing and outreach campaigns aimed at enrolling Medicaid-eligible populations. Provider-owned insurers generally use their own emergency rooms or community health centers to identify and enroll eligible but uninsured patients. Most states also use third-party enrollment brokers who help beneficiaries compare plan options and make a selection (CMS, 2016b).

In summary, the plan choice process in Medicaid differs significantly from the process in other settings such as employer-sponsored insurance, Medicare Advantage, and the ACA Marketplaces. The large share of passive enrollees means that state-defined auto-assignment rules play an outsized role in shaping insurer competitive incentives. This represents both a distinction from standard insurance markets - where demand is based on enrollee preferences and choices - and a powerful tool for states to use to shape the competitive environment.

\section{Textbox 2: MassHealth - Massachusetts' Medicaid Program}

Massachusetts operates a state-run Primary Care Clinician (PCC) plan alongside a set of private comprehensive Medicaid managed care plans. Many Medicaid recipients have a choice between the PCC and MMC plans, though the childless adults covered under Massachusetts' Medicaid expansion do not have the PCC option. Unlike most states, recipients who neglect to choose a plan are auto-assigned to both PCC and MMC plans rather than exclusively to MMC plans. In March 2015 about half of Massachusetts Medicaid recipients were enrolled in a private MMC plan.

Massachusetts contracts with six health plans: Boston Medical Center (BMC) HealthNet Plan, Fallon Community Health Plan, Health New England, Neighborhood Health Plan, Network Health, and Celticare (owned by Centene, and only available in the CarePlus program open to 
Massachusetts' Medicaid expansion population). Plans are not required to participate in all regions of the state. Two of the five plans, BMC HealthNet and Neighborhood Health Plan, are hospital-owned. The state does not restrict the number of health plans, but does require all plans to go through a procurement process. The state also contracts with a specialty managed care plan, MA Behavioral Health Partnership, to provide behavioral health services to individuals in the PCC plan.

Massachusetts pays plans based on regional administratively-set rates. Payments to health plans are risk adjusted using the DxCG risk adjustment system. The state is currently developing a variant of their current risk adjustment model that incorporates "Social Determinants of Health" information.

\section{Health plan payment design}

Health plan payment policies in Medicaid are complex and vary significantly across states. Medicaid managed care insurers are generally paid a monthly, risk-adjusted per enrollee payment (also known as a capitation rate) and may also receive supplemental payments for certain services or populations. In the rate development process, a "base payment" is developed based on the expected cost of the average Medicaid enrollee. The base payment is either set administratively or set as part of the procurement process (through competitive bidding or negotiation). The base payments are typically risk adjusted by multiplying the payment by individual (or group) risk scores to account for the health risks of a given insurer's Medicaid enrollees. Risk adjustment factors include demographic factors, health status, and eligibility type. Some states also use risk sharing methods such as risk corridors, reinsurance or stop-loss programs. Though states have flexibility to define state-specific health plan payment policies, federal regulations have led to some similarities across states. We discuss development of the base payment rate first, and then outline risk adjustment in more detail. 


\subsection{Rate Development}

Beginning in 2002, federal regulations required that capitation payments to MMC insurers be certified as "actuarially sound" based on cost and utilization data from Medicaid enrollees or a comparable population (MACPAC 2011). As part of the rate development process, states work with actuaries to develop a range of capitation rates based on national or state health care cost trends, provider reimbursement levels, fee-for-service data, and encounter data collected from participating insurers. ${ }^{10}$ The base capitation rates paid to insurers must lie within this range.

There are three basic methods for setting insurer capitation rates. Table 4 shows which states use each method. Some states use a single rate-setting method, whereas other states use a combination of multiple methods. In the first, administrative rate setting, states select a capitation rate within the actuarially sound range and communicate it to insurers during procurement. This method gives the state more control over its costs and avoids the administrative hassles of a bidding process. Rather than using its bargaining position to minimize costs while providing a given level of quality, the state has a set level of Medicaid spending and uses its position to maximize quality given that spending level.

A second method is for the state to conduct a competitive bidding process in which the actuarially sound range effectively serves as a price floor and ceiling. ${ }^{11}$ Interestingly, some states do not reveal the actuarially sound range during bidding but impose it on rates after bids are collected. The bidding method introduces price competition into Medicaid procurement and lets

\footnotetext{
${ }^{10}$ Encounter data includes records of services provided to enrollees in a given plan. As the quality of encounter data has improved over the years, some states have begun relying exclusively on encounter data (rather than fee-forservice data) for determining the actuarially sound rate range.

${ }^{11}$ Rate ceilings are a natural check on high prices, especially since beneficiaries do not pay higher premiums for plans that are more expensive to the state. Rate floors seem less natural given the state's desire to save money. Our understanding is that they are intended to prevent an MMC plan from mistakenly charging an unsustainably low price and then being forced to drop out mid-way through a contract period.
} 
the state save money if insurers submit low bids. However, just a handful of states use competitive bidding to set rates - perhaps due to a perception that plans that bid very low also offer lower-than-acceptable levels of quality.

The final method for rate setting is to conduct a negotiation with MMC plans. In these cases, states generally begin negotiations at the low end of the actuarially sound range. Insurers then

present their case for higher capitation rates, citing evidence of plan performance or quality. Negotiation was historically the norm for rate setting in MMC. However, today it is used in only a few states. The initial rate agreed upon during a competitive bid or negotiation is generally adjusted annually during the duration of the contract period to account for benefit changes and medical cost inflation.

\subsection{Risk Adjustment}

Starting from the base capitation payment (just discussed), states use various factors to adjust payment rates to account for differing health status of enrollees in each plan. Demographic factors - such as age, sex, geography, and Medicaid eligibility category - are generally included in rate adjustment. Over time, more states have incorporated medical diagnoses into risk adjustment. Risk scores are generated for each enrollee based on the included variables, and the average risk score of a plan's enrollees determines its risk-adjusted capitation rate. The precise method by which this occurs varies across states, as we describe below.

Diagnosis information may be gleaned from medical claims, encounter data, or pharmacy claims. The type of risk adjustment model chosen by a given state depends on the type and quality of claims data available to the state. For example, Florida moved from using Medicaid Rx (a model based on pharmacy claims) to the Chronic Disability Payment System (CDPS, a 
Table 4: Rate Setting and Payment

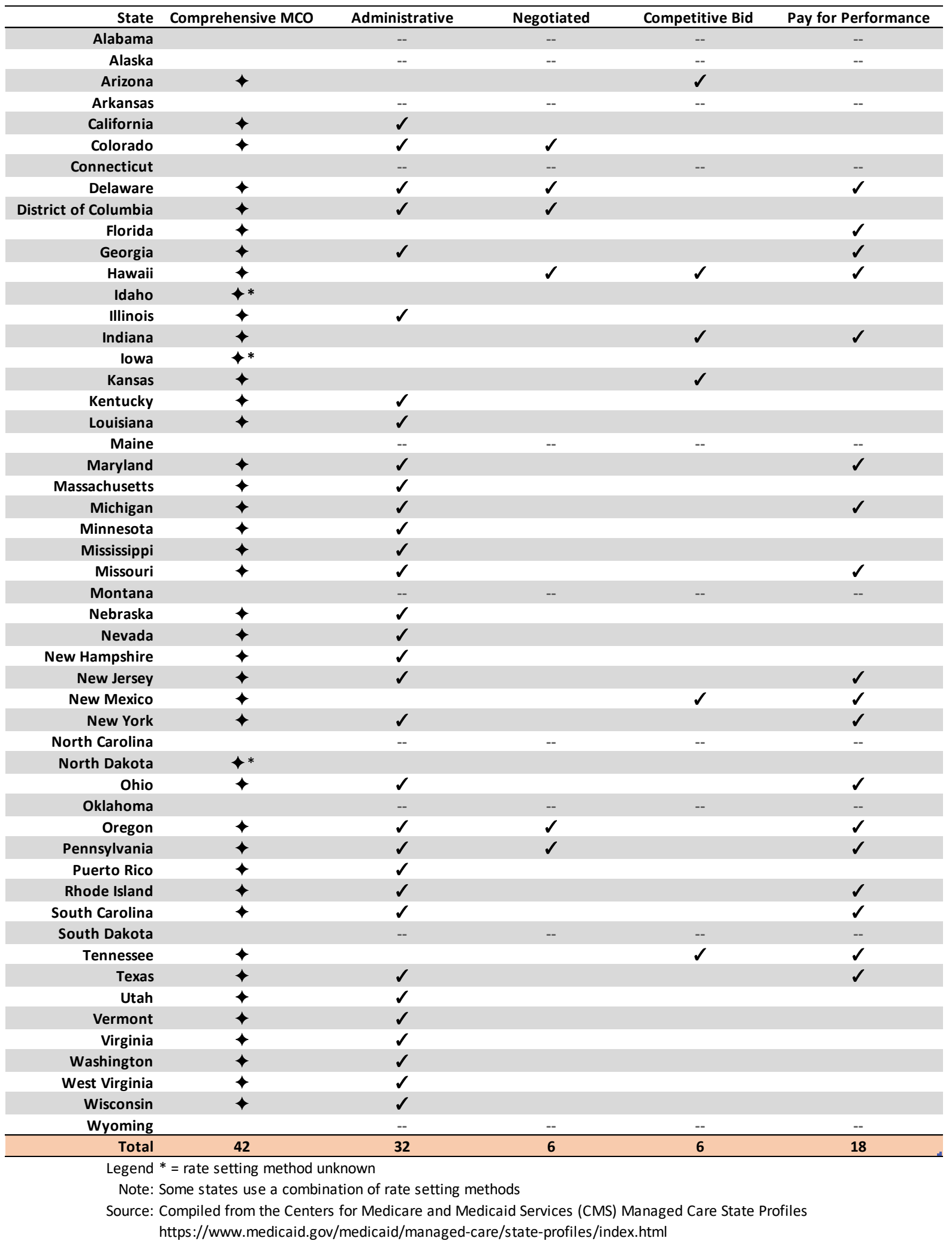


model based on medical diagnoses codes) after the reporting of encounter data improved. Moreover, a single state may use different risk-adjustment models for different populations. A study of 20 managed care programs in 2010 found that 17 states used a risk-adjustment model incorporating health status, though the exact models used varied by state (Courtot, 2012). CDPS, a risk-adjustment model originally developed for Medicaid plan payment, was most frequently used model. Eleven study states used CDPS, and three states used Adjusted Clinical Groups (ACG). Other models used include Ingenix Symmetry, Medicaid Rx, Clinical Pharmaceutical Groups (CRxG), and Diagnostic Cost Groups (DxCG).

States also differ in whether they implement risk adjustment based on concurrent diagnoses or diagnoses from the prior year (prospective) and in whether they use individual or "aggregate" risk adjustment (Winkelman and Damler 2008). Under all risk-adjustment methods, an average risk score for the plan is generated, and plan payments are equal to the base payment multiplied by the average risk score. The methods differ in how the average risk score is generated. Under individual risk adjustment - the standard method used in programs like Medicare Advantage and the ACA Marketplaces - plan payments are adjusted based on the risk scores of the individuals actually enrolled in the plan for each month. In this case, the plan's average risk score is the mean risk score of all of its enrollees in a given month. This method makes prospective risk adjustment difficult due to relatively short enrollment spells of most Medicaid recipients. Because of this difficulty, many states use "aggregate" risk adjustment, where a plan's per member per month payment in year $t$ is adjusted based on the average risk score of its population during year $t$-1. In this case, the plan's average risk score is the mean risk score of all of its enrollees during the prior year. In other words, plan payments are not adjusted based on the risk scores of their current enrollees but based on the risk scores of their prior enrollees. This solves 
the problem of short enrollment spells, but may make risk adjustment less accurate if the risk composition of a population changes across years. According to a 2008 survey, at that time most states used prospective aggregate risk adjustment (Winkelman, 2008).

Health plans may also receive payment adjustments in the form of incentive payments or efficiency adjustments. Some states incorporate incentive payments into capitation rates to reward insurers for meeting performance benchmarks. This payment model is often referred to as "pay-for-performance." Often, these payments are implemented as "quality withholds" where the state withholds a portion of a plan's payment until they can determine whether the plan met the quality benchmarks for the year. Similarly, states may adjust capitation payments for efficiency factors to incentivize plans to meet efficiency targets or reward plans for achieving cost savings. For example, rates may be adjusted to account for targeted or achieved reduction in unnecessary inpatient admissions.

\section{Textbox 3: Chronic Illness and Disability Payment System (CDPS)}

The Chronic Illness and Disability Payment System was developed to enable states to calculate risk adjusted payments to health plans for their Medicaid beneficiaries. CDPS groups ICD-9-CM diagnostic codes into 20 major diagnostic categories, which are further subdivided into subcategories by expected expenditure (i.e. high-cost, medium-cost, low-cost). To develop CDPS, regression analysis of Medicaid claims was used to identify which diagnosis in year one predicted expenditure in subsequent years. Then, clinical consultants helped to identify poorly defined diagnoses that were omitted from the set of diagnostic predictors to help mitigate the likelihood of inaccurate reporting. The model also features separate weights based on demographic and eligibility information, such as disability status.

CDPS uses individual diagnosis and demographic data to calculate individual risk scores which are used to adjust the payments made to health plans. CDPS+Rx is a revised version of CDPS that combines diagnostic predictors from CDPS with pharmacy claims based predictors using the Medicaid Rx risk adjustment model. Pennsylvania has used the CDPS $+\mathrm{Rx}$ risk adjustment model (Courtot, 2012). CDPS and CDPS+Rx can be used concurrently, based on current claims, or prospectively based on previous claims. (Kronick, 2000) 


\subsection{Risk Sharing}

In addition to risk-adjusted capitation payments to MMC plans, some states also use risk sharing methods such as risk corridors, stop-loss protection, and reinsurance for extremely high cost cases. Other policies related to risk sharing include service and population carve-outs and supplemental payments to health plans for certain services. The objectives of these policies vary, with risk corridors and stop-loss protection intended to protect insurers against financial risk and carve-outs and supplemental payments intended at least in part to weaken selection incentives. These methods are adopted differently across states and multiple risk sharing methods may be used collectively.

Risk corridors work like a profit-sharing scheme with the state. Plans whose claims costs exceed capitation payments by a given percentage are reimbursed for a portion of their losses. Conversely, a plan whose claims fall short of capitation payments by a given percentage must reimburse the state for a portion of their profits. With stop-loss protection, plans are not accountable for claims above a defined threshold. For example, New York limits plan risk for inpatient care to $\$ 100,000$ per enrollee per year, with the state covering remaining costs. Similarly, Arizona will cover $75 \%$ of an enrollee's annual inpatient claims above $\$ 25,000$ or $\$ 35,000$ (depending on the beneficiary) and $100 \%$ of inpatient claims exceeding $\$ 650,000$. Some states do not offer stop-loss protection or reinsurance but require that plans purchase private reinsurance coverage (Courtot, 2012).

In addition to these risk-sharing policies, carve outs of certain services and populations also act as risk sharing mechanisms. For example, New York automatically defaults low-birth weight babies into the fee-for-service program, protecting managed care plans from very high Neonatal Intensive Care Unit costs. Many states also default disabled individuals and other individuals 
with complex chronic conditions into fee-for-service, weakening selection incentives faced by managed care plans.

Some states also use supplemental "kick" payments to insurers for certain services or types of individuals. Supplemental payments are typically made to compensate managed care plans for services for which the state does not want them to bear the risk. The most common supplemental payment is for maternity services, to cover the cost of pre-natal care and delivery, with additional payments for low-birth weight babies. These payments act as a form of risk sharing to compensate insurers for the added cost of delivery. Pregnancy and childbirth are often difficult to include explicitly in the prospective risk-adjustment models typically implemented in Medicaid given that (1) there typically are not diagnoses from year $t-1$ indicating that a delivery will take place in year $t$ and (2) many pregnant women who have Medicaid coverage became eligible for Medicaid only when they become pregnant. Supplemental payments may also be made for HIV care, organ transplants, and other high-cost populations or services.

A final form of risk sharing that takes place in MMC is as part of the MMC plan's base payment. In some cases, MMC plans are not actually at risk for the spending of their enrollees. This typically occurs with provider-owned plans. The plan/provider organization is charged with managing the care of its enrollees and then reimbursed for any services that it provides to its enrollees on a fee-for-service basis. For example, the University of Utah has an MMC plan that participates in Utah's Medicaid program, and until 2013 this plan was reimbursed fee-for-service for all services it provided its enrollees. This form of plan payment is similar to another form of payment (known as "cost-plus" payment) that used to be common in Medicaid. Under cost-plus payment, MMC plans would present the state each year with records of their enrollees' spending. The state would then set each plan's payment equal to the plan's prior spending plus a mark-up 
to cover administrative costs and provide profits. While there was typically some negotiation between the state and the MMC plans, this form of payment was closer to fee-for-service reimbursement, leaving MMC plans with some short-term risk but limiting the medium- and long-term risk they faced. New York used "cost-plus" payment in its MMC program until 2008 when it transitioned to administratively-set regional rates with risk adjustment.

\section{Evaluation of health plan payment}

Medicaid does not have a single health plan payment system; instead, each state has its own payment system that may vary across different Medicaid populations. This makes an overall evaluation of health plan payment close to impossible. Thus, in this section we focus our attention on two types of evaluations. First, we present results on the statistical performance of each of the five risk adjustment models most commonly used in state Medicaid programs. For each model, we present R-squared and/or predictive ratio statistics from the initial research papers outlining the development of the models. While risk adjustment is far from the only component of Medicaid plan payment systems, it is an important component and is the only component that we know of that has been evaluated. Second, we review the small set of papers that have studied indirect consequences of plan payment systems, such as effects on health outcomes, benefit distortions, and risk selection of profitable enrollees by managed care plans. These papers provide insights into the inadequacies of the overall payment system, rather than focusing solely on risk adjustment. 


\subsection{Statistical Performance of Common Risk Adjustment Models}

The five most commonly used risk adjustment models that have been incorporated into Medicaid Managed Care payment systems are the Chronic Illness and Disability Payment System (CDPS), the Medicaid Rx model, the Adjusted Cost Groups (ACG) system, the Clinical Risk Groups (CRG) system, and the Diagnostic Cost Group (DxCG)/Hierarchical Condition Category (HCC) system. For each of these risk adjustment systems, the researchers who developed the system produced a report describing the development of the system and reporting some key statistics that are often used to evaluate payment system performance. While we recognize that there has been additional research on each of these systems, because of the large number of systems, we restrict our review to these initial reports except in a few exceptional cases. Additionally, we are limited to discussing the measures of performance that have been used, with the only available measures being R-squared statistics and predictive ratios. While these metrics do not directly measure the performance of the payment system with respect to common objectives such as inducing efficient sorting across plans and providing plans with incentives to provide efficient levels of benefits, (1) they are available and (2) they are not too different from metrics that do measure performance on these objectives (Layton et al. 2017).

The CDPS system was developed specifically for risk adjustment in Medicaid. It categorizes chronic conditions by the part of the body they affect. Each category is then divided into levels of severity. Kronick et al. (2000) report statistical measures of model performance using fee-forservice Medicaid data from seven states. They estimate separate weights for disabled and lowincome Medicaid recipients. The model is estimated prospectively, using diagnoses from the prior year to predict current year spending. The model performs particularly well for the disabled population, achieving an R-squared of 0.18 for this group. Performance is weaker for non- 
disabled adults and children enrolled in Medicaid, with R-squared statistics of 0.08 and 0.04 for these groups. When considering predictive ratios, the model also performs poorly for individuals with multiple chronic conditions, resulting in payments that fall below costs for these individuals. The developers of the CDPS also compare their model to the HCC and ACG systems, finding that with respect to the R-squared statistic the CDPS model outperforms both of its competitors in the Medicaid population they study. This result holds for all three eligibility categories: the disabled, non-disabled adults, and non-disabled children.

The Medicaid Rx Model uses pharmacy claims rather than diagnosis codes from claims to group individuals by chronic condition. This model is also prospective, using drug utilization from the prior year to predict current spending. Gilmer et al. (2001) show that this model performs better for disabled Medicaid recipients than it does for non-disabled adults and children using fee-for-service Medicaid data from California, Colorado, Georgia, and Tennessee (Gilmer et al. 2001). The model produces R-squared statistics of $0.15,0.11$, and 0.06 for the disabled, non-disabled adults, and non-disabled children, respectively. However, the developers of the model compare the model to the CDPS model and find that the CDPS model performs better.

The ACG model is similar to the CDPS in that it uses diagnoses to group individuals by condition. Unlike the other models, this model was developed on a commercial managed care population (Starfield et al. 1991). The developers found that in that population, the model produced an R-squared statistic of 0.19 , implying reasonably good performance. However, other work indicates much weaker performance in a Medicaid population (Kronick et al. 2000).

The CRG model is also a diagnosis-based model. It differs from the ACG and CDPS models in that the categories to which it assigns individuals are mutually exclusive, i.e. each individual belongs to a single category. The developers of this model find that in a Medicare population the 
model produces an R-squared of 0.11 when used prospectively and around 0.43 when used concurrently (Hughes et al. 2004). The model performs reasonably well across all subgroups analyzed by the developers, with predictive ratios ranging from around 0.9 to around 1.1, implying that for these groups costs never exceed or fall below revenues by more than $10 \%$. This is not surprising given that the authors only analyzed subgroups of individuals incorporated into the model (age, number of chronic diseases, etc.).

The DxCG/HCC system is another diagnosis-based risk adjustment model. The developers of this model find that it performs well in a Medicaid population, with an R-squared statistic between 0.21 and 0.23 (Ash et al. 2000). The developers analyze predictive ratios for a variety of medical condition-based subgroups. They find that the DxCG model dramatically outperforms basic age/sex risk adjustment and that it performs well overall: All predictive ratios exceed 0.8 with the exception of the arthritis, and sexually transmitted diseases groups, and many groups including most cancers, heart failure, diabetes, and alcohol/drug dependence have predictive ratios close to 1.0.

\subsection{Indirect Consequences of Inadequate Risk Adjustment}

While statistical measures of payment system performance can be useful - in that these measures are similar to measures derived from a formal model of a regulator's objective in addressing adverse selection incentives (Layton et al. 2017) - studies of the actual consequences

of payment systems for enrollment and health outcomes provide a more complete picture of whether a payment system achieves desired goals. Here, we focus on studies that consider potential indirect outcomes of payment systems. 
Frank, Glazer, and McGuire (2000) study insurer incentives to distort plan benefits to attract health enrollees in a Medicaid population. They construct a theoretical model that provides a measure of an insurer's incentive to distort coverage for a particular service, calling the insurer's behavior in response to that incentive "service-level selection." They then use the measure to evaluate service-level selection incentives in Michigan's Medicaid program using data from feefor-service Medicaid recipients. They show that insurer service-level selection incentives are particularly strong for mental health services and that this result holds under a payment system with no risk adjustment and systems using ACGs and HCCs. They also show that both the HCC and ACG risk adjustment systems tend to weaken distortionary incentives.

An early paper showing evidence of MMC plan behavior consistent with a potential failure of an MMC plan payment system was Currie and Fahr (2005) who study the effect of the switch to managed care on the composition of the Medicaid caseload. They find that Medicaid enrollment increases for poor white and Hispanic children but decreases for black children. They also find that enrollment decreases among toddlers but not for school-aged children. Given that toddlers and black children are generally sicker than other Medicaid populations (Currie and Fahr 2005), these results are consistent with "cream-skimming" behaviors, potentially implying that the payment systems in place during the study period (1989-1994) were inadequate.

Kuziemko et al. (2013) study transitions to managed care in Texas' Medicaid program. Again, they focus on evidence of cream-skimming behavior among MMC plans, though they focus on the mechanism by which plans engage in cream-skimming rather than the ultimate enrollment consequences. Specifically, they show that when Texas counties transitioned from fee-for-service Medicaid to MMC, black infant mortality rates increased while Hispanic infant mortality rates decreased. They argue that this is consistent with plans reducing quality of care 
for high-cost Medicaid recipients and improving quality of care for low-cost Medicaid recipients because the average black birth costs almost twice as much as the average Hispanic birth. Again, this suggests that the MMC plan payment system was imperfect in Texas during the authors' study period (1993-2001).

Clearly, more research is needed in this area. Medicaid is a population with extreme variation in health care spending, with kids and pregnant women sometimes combined in the same risk pool as the disabled and low-income aged individuals. This unpriced risk heterogeneity represents a challenge for policymakers seeking to minimize adverse selection problems. Thus, work focusing on more recent years and investigating standard questions about the extent of selection in these MMC markets and the adequacy of current payment systems for compensating plans for that selection is critical to improving the economic performance of these markets.

\section{Ongoing issues and reforms}

There is a great deal we do not know about the economics of Medicaid managed care. MMC market design, in particular, is an issue that is ripe for study and reform, and an issue clearly linked to decisions about the form of health plan payment. As a large and growing budget item, Medicaid reform is an issue high on states' priority lists. MMC regulation is also a federal priority, with the Center for Medicare and Medicaid Services (CMS) in 2016 issuing the first large regulatory revamp in over a decade. Finally, as we have emphasized, the principles of regulated competition have been applied to Medicaid only incompletely and in varying ways across states. This makes Medicaid a potential "laboratory for regulated competition" - a setting where researchers can test ideas underlying regulated competition and inform state Medicaid 
reform efforts. This sort of research can improve our understanding of the consequences of various policies underlying the regulated competition model.

In this section, we highlight several areas where the principles of regulated competition could be more fully applied in MMC. We discuss both potential reforms suggested by these principles and the actual reform activity in these areas.

\subsection{Enrollee Premiums}

The lack of enrollee premiums in Medicaid is a major departure from the basic idea of regulated competition, for instance as laid out by Enthoven and Kronick (1989). Price signals are central to the standard economic theory of market functioning. They steer consumers towards lower-cost options and also let them indicate their level of valuation for higher-quality goods by paying extra. These demand signals, in turn, encourage producers to cut costs and improve quality. This standard form of competition is not possible in Medicaid where enrollees can typically choose any plan for free.

The implications of Medicaid's "price-free" competition model are not well understood. Its consequences are particularly interesting because of well-known market failures associated with price competition in insurance markets with adverse selection (Akerlof 1970; Rothschild and Stiglitz 1976). One way of mitigating these inefficiencies is to cross-subsidize price differences between plans of varying generosity, lowering the relative price of the (more generous) adversely selected plan. Cross-subsidizing price differences can lead to two beneficial effects. First, it can improve the sorting of beneficiaries across plans by narrowing price differences towards cost differences for the marginal enrollee (or "marginal costs"; see Cutler and Reber 1998; Einav, 
Finkelstein, and Cullen 2010). Second, it can increase the quality of plans in equilibrium, making it possible for generous plans to survive (Miyazaki 1977; Handel, Hendel, and Whinston 2015).

Medicaid's zero-premium design works like a $100 \%$ subsidy on price differences. For improving sorting among plans, this is only optimal if marginal cost differences are truly zero. Recent evidence from Layton, Geruso, and Wallace (2016) studying New York Medicaid suggests that cost differences may in fact be quite large (as large as 30\% among MMC plans in New York City). Thus, Medicaid's 100\% cross-subsidies likely go too far for the purpose of optimal sorting (i.e., "too many" individuals enrolling in high-cost plans and "too few" enrolling in low-cost plans).

For increasing equilibrium quality, the effects of Medicaid's subsidy policy are ambiguous. On the one hand, firms are likely to compete more on quality when enrollees are not price sensitive (Dorfman and Steiner 1954). Further, the absence of premiums may eliminate a powerful tool for low-cost, low-quality plans to selectively attract profitable consumers - the mechanism at the heart of the Rothschild and Stiglitz (1976) model. ${ }^{12}$ On the other hand, the zero-premium setup means that Medicaid must either set insurer prices administratively or (if bidding is used) impose caps on price bids. Otherwise, a plan could charge an arbitrarily high price and make unlimited profits. Binding price caps can reduce equilibrium quality because a plan cannot raise its price to pay for the associated costs of improving quality. Thus, the net effect on quality is ambiguous. Additional research is needed to understand the tradeoffs involved with Medicaid's price-free competitive model.

\footnotetext{
12 Adverse selection can still occur in zero-premium Medicaid markets, but the mechanism would have to be different. Sicker people might be more aware that certain plans are better quality (or more likely to actively choose a plan). Alternatively, the sick and healthy might value different aspects of quality - e.g., the sick might value good specialist networks, whereas the healthy value good PCP networks. The latter is the mechanism in the literature on "service-level selection" (Frank, Glazer, and McGuire 2000; Ellis and McGuire 2007).
} 
We are not aware of any states that apply different enrollee premiums to MMC plans based on their price bids. Several states have recently adopted reforms requiring higher-income enrollees (above the poverty line) to pay modest premiums to enroll in Medicaid. ${ }^{13}$ Some of these reforms allow lower-income enrollees to get slightly more generous benefits if they pay a modest premium (though they are not disenrolled if they fail to pay). However, these reforms do not apply different premiums to managed care insurers based on their price bids, costs of care, or observed/unobserved quality.

One concern with premiums in Medicaid is that even modest amounts may deter enrollment (Dague 2014), leaving low-income individuals uninsured. This concern, however, can be addressed within the regulated competition framework if premiums can be negative - that is if the state can rebate money to consumers. The state could make a benchmark plan (e.g., the most expensive plan) free and share savings with consumers if they choose a cheaper option. There are questions about whether such a system would be administratively feasible, but if so, it could allow for premium differences without deterring coverage.

\subsection{Competitive Procurement}

Absent enrollee premiums, the main way Medicaid programs can encourage insurers to compete on prices is via states' power to limit and shape choices. We highlight two "competitive procurement" tools: regulators' power to determine plan availability and to set auto-assignment rules.

${ }^{13}$ For instance, five states (Arkansas, Indiana, Iowa, Michigan, and Montana) have received federal waivers allowing them to charge premiums to enrollees newly eligible under the ACA (Kaiser Survey 2016). The "Healthy Indiana Plan" is a typical example. It requires enrollees between $101-138 \%$ of poverty to pay premiums of $2 \%$ of income (about $\$ 25 /$ month) to stay enrolled. 
One way states can encourage competition is by selecting insurers in the procurement process based on criteria like price and quality. If these criteria are clear in advance and there is a credible threat of rejection, the procurement process may encourage insurers to lower prices and/or improve quality. Notice the counter-intuitive logic: by limiting choice (or at least threatening to do so), the program promotes competition on desired outcomes. While many states use a "competitive" process to select MMC plans, the extent to which there is a real threat of rejection is unclear. Some states (like Missouri) explicitly limit the number of insurers that can participate in Medicaid (either statewide or regionally). The desired number of MMC plan contracts may be communicated to insurers during the RFP process, as in the case of Iowa's 2015 RFP release. ${ }^{14}$ But it is not clear how binding these limits are or how states select the winning insurers. In Minnesota's 2012 RFP, a scoring rubric based on quality, efficiency, and cost was used to select the top three plans in each region (Spencer 2012).

Another way of using plan availability to encourage competition is for states to accept all insurers but limit plan availability for certain enrollees (e.g., new enrollees) to plans with the lowest prices. This method has been used in two hybrid Medicaid/exchange programs: Massachusetts' pre-ACA CommCare program and Arkansas' "private option" Medicaid expansion. It has the advantage that the Medicaid program can limit choice without having to kick current enrollees out of an existing plan if it fails in the competitive procurement process.

An additional competitive procurement tool is states' power to auto-assign passive beneficiaries. In theory, plans with lower prices (or better quality) could be favored with larger shares of auto-assignees. Interestingly, while ten states consider quality in auto-assignment, as

\footnotetext{
${ }^{14}$ Iowa stated plans to reward 2 to 4 MMC plan contracts in the 2015 Iowa Medicaid Managed Care RFP release (Herman, 2015).
} 
far as we know only Kentucky appears to use insurer prices as a factor (Marton et al. 2016). Indeed, 23 states use auto-assignment to "balance enrollments" across plans, giving larger shares to plans with fewer people (Kaiser Survey 2016). This method has the odd (and likely perverse) effect of favoring plans that actively choosing enrollees have signaled to be less desirable. Given the high rates of auto-assignment in many states ( $45 \%$ in the median state), a state's decision of how to allocate these enrollees is likely to have a significant effect on MMC plan behavior. Overall, competitive auto-assignment seems like a simple and underexplored avenue for reform.

\section{Textbox 4: Kentucky's Medicaid Program}

In 2011, Kentucky ended its PCCM program and expanded mandatory enrollment in private risk-based managed care plans statewide. The state chose to contract with three managed care plans: Aetna Better Health of Kentucky (owned by Aetna), Wellcare of Kentucky (owned by Wellcare), and Kentucky Spirit (owned by Centene). More recently, the state also initiated a contract with Anthem to serve its Medicaid expansion population. All plans are comprehensive Medicaid Managed Care plans and there are no service "carve-outs."

In April 2011, the state issued an RFP seeking bids from managed care insurers to cover Medicaid recipients residing outside the Louisville area. They received bids from 9 insurers and chose three. After the state selected the three plans, regional rates were negotiated with each managed care plan. Overall, Wellcare negotiated the highest rates and Spirit negotiated the lowest rates. It is not clear whether a promise of favorable auto-assignment to plans with lower rates was part of the negotiation process, but ultimately the state did assign more enrollees to the lowest cost plan in each region than to the other plans (Palmer et al. 2012).

In November 2011, the state auto-assigned all Medicaid recipients to one of the three plans and then opened a 90 day open enrollment period during which recipients were able to switch to a different plan (Marton et al. 2016). The auto-assignment algorithm took into account prior physician relationships, family relationships, "load balancing," and cost (Palmer et al. 2012).

Following auto-assignment, there was substantial switching out of the Kentucky Spirit plan, which had the lowest negotiated rate and was viewed as low-quality, especially in one region where it was unable to contract with a dominant provider group (Marton et al. 2016). Marton et al. find that sicker recipients were more likely to switch out of Spirit and into Wellcare, potentially leading to an adverse selection problem for Wellcare. However, the advantageously selected plan, Spirit, exited the market in 2013, citing large financial losses under the low rate it had negotiated with the state. 


\subsection{Scope of Benefits and Carve-Outs}

Standard theory suggests that managed care plans will have more efficient cost control incentives if they cover a broad set of benefits. An insurer that covers all benefits will internalize "offset effects," whereby benefit changes in one area affect spending in another. For instance, reducing access to prescription drugs has been shown to increase hospitalizations for the elderly (Chandra, Gruber, and McKnight 2010). An insurer that covered only prescription drugs (as in Medicare Part D) would not internalize these offset effects (Starc and Town 2016; Lavetti and Simon 2016).

In the presence of adverse selection, however, it may be efficient to "carve-out" certain services that are used by individuals with predictably high costs (Frank, Glazer, and McGuire 2000; Ellis and McGuire 2007). If these services are not carved out and risk adjustment is inadequate, then insurers face incentives to inefficiently ration these services. Because of this selection issue, it can be better for the state to pay for a service via fee-for-service or to contract it out separately to a specialized plan (e.g., a behavioral health care organization), despite the potential inefficiency induced by non-internalized offset effects.

In Medicaid, benefits like behavioral health, prescription drugs, and dental care are in fact often "carved out" of managed care contracts. However, the recent trend has been to begin carving some of these services back into managed care contracts. The shift in strategy may be driven by more favorable federal policies for drug reimbursement or improved integration of dental and behavioral health provider networks by insurers. The shift may also be driven by improvements in state MMC plan payment systems that use sophisticated risk adjustment 
systems that combat the selection-related inefficiencies that the carve-outs may have partially been intended to prevent. Alternatively, even without a carve-out insurers may still subcontract with more specialized insurers to provide behavioral health services. ${ }^{15}$

More research is needed to understand the efficiency consequences of these carve-outs. Given that many states are currently shifting away from carve-outs, there should be many natural experiments with which researchers can study their consequences in the coming years.

\subsection{Plan Regulation and Payment}

A key feature of regulated competition is that the market designer regulates benefits and risk adjusts payments to offset incentives to stint on quality due to adverse selection. MMC regulators have widely adopted both approaches: benefits are heavily regulated (indeed, typically completely specified) and risk adjustment is standard. But there are several ways in which these areas are ripe for reform.

First, while states are increasingly adopting risk adjustment methods that use enrollee diagnoses (Kaiser Survey 2016), these methods are still imperfect. For instance, many states use "aggregate" risk adjustment, which is based on the risk scores of a plan's enrollees in the prior year (see discussion in Section 3). This is likely to offset selection incentives less well than the standard risk adjustment methods based on a plan's actual enrollees (though it may also reduce incentives to upcode). Further, an important lesson from the literature is that when risk measures are imperfect, optimal risk adjustment "over-pays" based on observed risk to compensate for adverse selection on unobserved risk (Glazer and McGuire 2000). We are not aware of any states that have tested this approach.

\footnotetext{
${ }^{15}$ Section 2 includes more detail on the incentives to carve out certain Medicaid service.
} 
Second, some aspects of quality - like how well the insurer coordinates care or how smooth its claims-paying process is - are difficult to measure and regulate in plan contracts. Instead, Medicaid programs are increasingly using quality reporting and pay-for-performance incentives to encourage insurers to improve on these softer aspects of quality. ${ }^{16}$

Third, Medicaid programs are increasingly specifying in contracts that plans pay their providers using value-based purchasing or non-fee-for-service "alternative" payment models. This new focus of Medicaid programs has the goal of reforming the delivery system. In 2016, 12 states had contracts requiring or encouraging alternative payments, with eight states planning to adopt such contract provisions in 2017 (Kaiser Survey 2016). In addition to these plan payment requirements, several states are adopting reforms to require plans to provide services that address the "social determinants" of health, including screening beneficiaries and referring them to nonmedical community support services.

Finally, Medicaid programs are increasingly adopting regulations on medical loss ratios (MLRs), to constrain plan profits and administrative costs. New federal regulations in 2016 mandated an $85 \%$ minimum MLR for Medicaid plans, though many states already had similar or higher requirements. MLR regulation has little basis in standard regulated competition principles - though it may make sense given the limits on price competition in the Medicaid program. However, it is unclear how it can work in a program where provider-owned plans are so common. These plans can directly adjust their costs via the transfer price embedded in their plan's payment rates to the owning provider.

\footnotetext{
${ }^{16}$ In 2015 , nearly all states with risk-based managed care had quality reporting programs, and 28 of the 39 states had pay-for-performance initiatives. Many states are adopting or expanding these initiatives in 2016 and 2017.
} 


\section{References}

Akerlof, G. (1970). The Market for "Lemons": Quality Uncertainty and the Market Mechanism. The Quarterly Journal of Economics, 84(3), 488-500.

Ash, Arlene, Randall Ellis, Gregory Pope, et. al. (2000). "Using Diagnoses to Describe Populations and Predict Costs". Health Care Finance Review, 21 (3), Spring: 7-28.

Brooks, Tricia, Sean Miskell, Samantha Artiga, et. al. (2016). Medicaid and Chip Elligibity, Enrollment, Renewal, and Cost-Sharing as of January 2016: Findings from a 50-State Survey. Kaiser Family Foundation. January 21. Accessed January 10, 2017. http://kff.org/report-section/medicaid-and-chip-eligibility-enrollment-renewal-and-costsharing-policies-as-of-january-2016-premiums-and-cost-sharing/.

Center for Medicaid and State Operations. (2006). "Letter to State Medicaid Directors". Center Medicaid and Medicare Services. Retrieved from https://www.medicaid.gov/FederalPolicy-Guidance/downloads/SMD06010.pdf

Chandra, A., Gruber, J., \& McKnight, R. (2010). Patient Cost Sharing in Low Income Populations. The American Economic Review, 100(2), 303-308.

Courtot, B., Coughlin, T. A., \& Lawton, E. A. (2012). "Medicaid and CHIP Managed Care Payment Methods and Spending in 20 States." Office of the Assistant Secretary for Planning and Evaluation, US Department of Health and Human Services. Urban Institute, Washington, DC.

Currie, Janet and John Fahr. (2005). "Medicaid managed care: effect on children's Medicaid coverage and utilization". Jounral of Public Economics, 89 (1), January: 85-108.

Culter, D., \& Reber, S. (1998). Paying for Health Insurance: The Trade-Off between Competition and Adverse Selection. The Quarterly Journal of Economics, 113(2), 433466.

Dague, Laura (2014). "The effect of Medicaid premiums on enrollment: a regression discontinuity approach." Journal of Health Economics, 37, p. 1-12.

Dockendorf, Megan, Elizabeth Larson and Angie WasDyke. (2014). "MO Healthnet Managed Care Rate Development July 1, 2015- June 30, 2016”. Mercer. November 10, 2014. Accessed January 10, 2017. https://dss.mo.gov/business-processes/managed-care/biddervendor-documents/mercer-presentationmohealthnet-managed-care-rate-development.pdf

Dorfman, R., \& Steiner, P. (1954). Optimal Advertising and Optimal Quality. The American Economic Review,44(5), 826-836.

Draper, D. A., Hurley, R. E., \& Short, A. C. (2004). "Medicaid managed care: the last bastion of the HMO?." Health Affairs, 23(2), 155-167.

Einav, Liran, Amy Finkelstein, and Mark Cullen (2010). Estimating Welfare in Insurance Markets Using Variation in Prices. Quarterly Journal of Economics. vol. 123, no 3, August, pp: 877-921.

Ellis R.P. and McGuire, T.G. (2007) "Predictability and Predictiveness in Health Care Spending," Journal of Health Economics 26(1): 25-48.

Enthoven A, Kronick R. (1989). "A consumer choice health plan for the 1990s". New England Journal of Medicine;320:29. 
Frank, Richard, Haiden Huskamp, Thomas McGuire, and Joseph Newhouse. "Some Economics of a Mental Health Carve Out." Archives of General Psychiatry, vol 56, October, 1996.

Frank, Richard, Jacob Glazer, and Thomas McGuire. (2000) "Measuring Adverse Selection in Managed Health Care." Journal of Health Economics, vol 19:829-854.

Geruso M, Layton T, and Wallace J (2016). "Are All Managed Care Plans Created Equal? Evidence from Random Plan Assignment in New York Medicaid Managed Care". In preparation.

Gifford, Kathy, et al. (2011). "Profile of Medicaid Managed Care Programs in 2010: Findings from a 50-State Survey, A."

Gilmer, Todd, Richard Kronick, Paul Fishman, and Theodore Gianats. (2001). "The Medicaid Rx Model: Pharmacy-Based Risk Adjustment for Public Programs”. Medical Care, 39 (11), November: 1188-1202.

Glazer, J acob and Thomas G. McGuire. (2000). "Optimal Risk Adjustment in Markets with Adverse Selection: An Application to Managed Care." American Economic Review, 90(4): 1055-1071.

Handel, Ben, Igal Hendel and Michael Whinston (2015). "Equilibria in Health Exchanges: Advrse Selection vs. Reclassification Risk Supplement. Econometrica 83(4): 1261-1313.

Herman, Bob (2015). "Iowa opens Medicaid program to managed-care bidding." Modern Health Care. Retrieved from http://www.modernhealthcare.com/article/20150224/NEWS/150229971.

Hughes, J, Averill R, Eisenhandler J, et. al. (2004)." Clinical Risk Group's (CRG): a classification system for risk-adjusted capitation based payment and health care management". Medical Care, 42(1), January: 81-90.

Kaiser Family Foundation (KFF, 2011). "A Profile of Medicaid Managed Care Programs in 2010: Findings from a 50 state survey." September 13 Retrieved from http://kff.org/medicaid/report/a-profile-of-medicaid-managed-care-programs-in-2010findings-from-a-50-state-survey/

Kaiser Family Foundation (KFF, 2016). "Total Medicaid Spending.” September. The Henry J Kaiser Family Foundation. http://kff.org/medicaid/state-indicator/total-medicaidspending/?currentTimeframe $=0$

Kaiser Family Foundation (KFF, 2017a). "Medicaid Benefits: Prescription Drugs". State Health Facts: Medicaid Benefits Data Collection. Retrieved from http://kff.org/medicaid/stateindicator/prescription-drugs/?currentTimeframe $=0$

Kaiser Family Foundation (KFF, 2017b). "Medicaid MCO Parent Firm Activity, by State and Insurance Market". State Health Facts: Medicaid Managed Care Market Tracker. Retrieved from http://kff.org/other/state-indicator/medicaid-mco-parent-firm-activity-bystate-and-insurance-market/?currentTimeframe $=0$

Kronick, Richard, Todd Gilmer, Tony Dreyfus, and Lora Lee. (2000). "Improving Health-Based Payment for Medicaid Beneficiaries". Healthcare Financing Review, 21 (3), Spring : 2964. 
Kuziemko, Ilyana, Katherine Meckel, and Maya Rossin-Slater. (2013). "Do Insurer's Risk Select Against Each Other? Evidence from Medicaid and Implications for Health Reform". NBER Working Paper 19198.

Layton, Timothy, Michael Geruso, and Jacob Wallace. (2016). "Are All Managed Care Programs Created Equal? Evidence From Random Plan Assignment in New York Medicaid Managed Care." In preparation.

Layton, Timothy, Randall Ellis, Thomas McGuire, and Richard Van Kleef. (2017) "Measuring Efficiency of Health Plan Payment Systems in Managed Competition Health Insurance Markets." Journal of Health Economics. Forthcoming.

Lewin Group, ACAP, and MHPA. "Medicaid Non-Emergency Out-of-Network Payment Study." July 2009.

Lavetti, Kurt and Kosali Simon. (2016). "Strategic Formulary Design in Medicare Part D Plans" Revise and Resubmit at American Economic Journal: Economic Policy

Marton, James, Aaron Yelowitz, and Jeffrey Talbert. (2016). "Medicaid Program Choice, Inertia, and Adverse Selection". Under revision Journal of Health Economics.

Medicaid and Children's Health Insurance Programs: Essential Health Benefits in Alternative Benefit Plans, Eligibility Notices, Fair Hearing and Appeal Processes, and Premiums and Cost Sharing; Exchanges: Eligibility and Enrollment. (Medicaid and Children's Health 2013) 78 Federal Register 42159. September 15.

Medicaid and CHIP Payment and Access Commission (MACPAC, 2011). "Report to the Congress: The Evolution of Managed Care in Medicaid."

Medicaid and CHIP Payment and Access Commission (MACPAC, 2017). "Mandatory and Optional Benefits." Retrieved from https://www.macpac.gov/subtopic/mandatory-andoptional-benefits/

Mershon, E. (2016, May 23). "Medicaid Plans Succeed in Obamacare Exchange as Others Struggle." Washington Health Policy: Week in Review. Retrieved from http://www.commonwealthfund.org/publications/newsletters/washington-health-policyin-review/2016/may/may-23-2016/medicaid-plans-succeed-in-obamacare-exchange-asothers-struggle

Miyazaki, H. (1977). "The Rat Race and Internal Labor Markets." Bell Journal of Economics, $8(2): 394-418$

Office of the Inspector General (OIG), US Department of Health and Human Services. (2014). "State Standards for Access to Care in Medicaid Managed Care"

Rothschild, M., \& Stiglitz, J. (1976). Equilibrium in Competitive Insurance Markets: An Essay on the Economics of Imperfect Information. The Quarterly Journal of Economics, 90(4), 629-649.

Smith, Vernon, Kathleen Gifford, and Eileen Ellis. (2016). Medicaid Reforms to Expand Coverage, Control Costs, and Improve Care: Results from a 50-State Medicaid Budget Survey for State Fiscal Years 2015-2016. Kaiser Family Foundation. Accessed January 10, 2017. http://files.kff.org/attachment/report-medicaid-reforms-to-expand-coverage- 
control-costs-and-improve-care-results-from-a-50-state-medicaid-budget-survey-forstate-fiscal-years-2015-and-2016

Sparer, Michael. (2012). "Medicaid managed care: Costs, access, and quality of care". Robert Woods Johnson Foundation.. September. Accessed January 10, 2017. http://www.rwjf.org/content/dam/farm/reports/reports/2012/rwjf401106.

Spencer, D, Dybdal, K \& Johnson, K. (2012). "Stakeholder Analysis of Medicaid Competitive Bidding in Minnesota: Final Report." State Health Access Data Assistance Center (SHADAC). Retrieved from http://archive.leg.state.mn.us/docs/2014/mandated/140686.pdf

Starc, Amanda and Robert J. Town, (2016) "Externalities and Benefit Integration in Health Insurance", NBER Working Paper 21783.

Starfield B, Weiner J, Mumford L, and Steinwachs D. 1991. Ambulatory Care Groups: A Categorization of Diagnoses for Research and Management. Health Services Research, vol. 26(1): 53-74.

US Department of Health and Human Services Centers for Medicare and Medicaid Servies. (CMS 2016a). Medicaid \& CHIP: August 2016 Monthly Applications, Eligibility Determinations and Enrollment Report. Novemer 3. Accessed January 10, 2017. https://www.medicaid.gov/medicaid/program-information/downloads/august-2016enrollment-report.pdf.

US Department of Health and Human Services Centers for Medicare and Medicaid Servies. (CMS 2016b). Medicaid and Managed Care Enrollment and Program Characteristics 2014. Spring. https://www.medicaid.gov/medicaid-chip-program-information/bytopics/data-and-systems/medicaid-managed-care/downloads/2014-medicaid-managedcare-enrollment-report.pdf

Winkelman, R \& Damler, Rob. (2008). "Risk adjustment in state Medicaid programs." Health Watch 57: 1-34. 